\title{
American Pediatric Society 2010 Presidential Address-Epigenetics: A Science of Biological Adaptation-Lessons for Academic Pediatrics
}

\author{
SHERIN U. DEVASKAR
}

Department of Pediatrics, David Geffen School of Medicine at University of California Los Angeles, University of California Los Angeles School of Medicine, Los Angeles, California 90095

$\mathrm{M}$ embers, colleagues, and guests, I have had the distinct privilege of serving as your President. This past year has been filled with excitement and invigoration as we revitalized the American Pediatric Society (APS). We have launched a major campaign targeted at "Taking back APS." I will provide a brief report on the state of the APS after my Presidential address.

I would like to begin by describing our new transformed world. With major technological advances has come globalization, our world is shrinking and the stark contrast of imbalances is becoming apparent. Although our environment is ever changing, the world's children remain our collective focus. To improve their health and lives, we must embark on, exchange, share, and join hands in meeting their needs. What better way than to join forces in the four important areas, namely, 1) research to bring new advances in prevention, diagnosis, and therapy, 2) health care delivery that reaches all children of the world, 3) advocacy toward making our collective voices on behalf of all children heard by policy makers around the world, perhaps igniting an United Nations summit on Children's Health, and 4) train the next generation of Pediatricians to carry the torch for the sake of children worldwide.

Although some may consider this idealism, it may be important to see what we are encountering in our new everchanging world? Most of the children in the world reside in areas where resources are limited. Currently in the world, 1 billion individuals per year face food insecurity in the form of limited availability, accessibility, and utilization. Of this number, 280 million are children. Furthermore, the impact of climate change, wars, and natural disasters on children should not be underestimated. In contrast to this growing problem, the children in our neighborhoods face a different problem. For instance, $14 \%$ of children in the United States are obese. What is clearly surfacing is that our children are encountering the complications of obesity, such as glucose intolerance and

Received November 15, 2010; accepted November 15, 2010.

Correspondence: Sherin U. Devaskar, M.D., 10833 Le Conte Avenue, Room B2-375 MDCC, Los Angeles, CA 90095; e-mail: sdevaskar@mednet.ucla.edu

Presented at the 2010 Annual Meeting of the Pediatric Academic Societies, Vancouver, British Columbia, Canada. hypertension, which may predispose them to premature death. What is worse is that our children are overweight and obese earlier in life. The prevalence of both these conditions in 2-5-y-old children in the different ethnic groups already shows that even at the tender age, $10-25 \%$ of children are already affected (Fig. 1A) (1). This early developmental trend points toward an intrauterine origin. In essence then, there exists a world health imbalance, with perinatal mortality encountered in great numbers where resources are limited. The children there are facing food insecurity and the consequences of infection and disturbed immune function. In contrast, in industrialized countries with adequate resources, postponement of starting a family with other stressors has contributed to high rates of infertility and the children who exist are obese facing chronic diseases earlier in life. Both ends of this nutritional spectrum are leading to a shortened life span, perhaps shorter than the parent generation. The surviving children face the onset of adult diseases earlier in life with permanent changes that last a lifetime (Fig. 1B).

Thus, the nutritional status of the fetus seems to affect the newborn, infant, and child. These changes during the vulnerable period of development persist into adolescence and adulthood affecting the next generation. In many parts of the world, adolescents are having children and hence the circle of life continues. These nutritional perturbations during early life also manifest in the form of chronic diseases during the aging process, thus the beginnings predetermine the end of life as well (Fig. 1C).

Furthermore, the developing brain is imprinted by nutritional changes with altered neuronal connectivity and function, resulting in an increased incidence of autism, where childhood obesity and cancer are prevalent, and psychoses, where undernutrition is prevalent. These nutritional imbalances may account for the increasing incidence of psychiatric disorders in our children as well.

In the United States, Michelle Obama, our first lady has initiated a Campaign called "Lets Move" to make a difference to $10 \%$ of US children and $18 \%$ of US adolescents who are obese, costing the country 147 billion dollars/y. This campaign is targeted at healthy eating habits seen by the vegetable garden on the White house grounds and overcoming physical inactiv- 


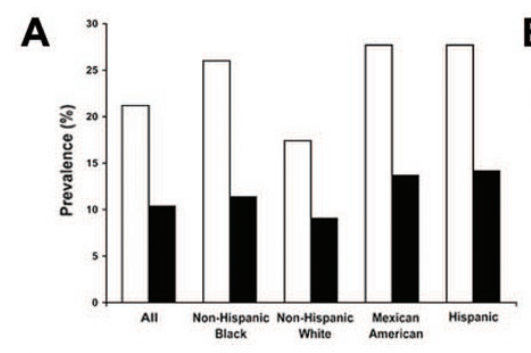

D

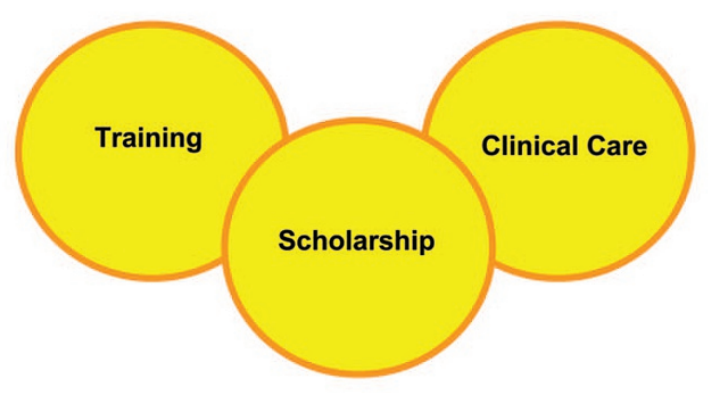

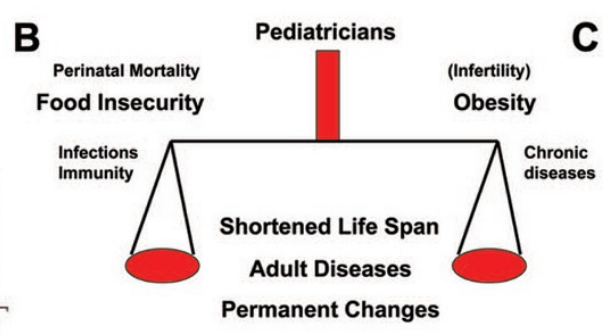

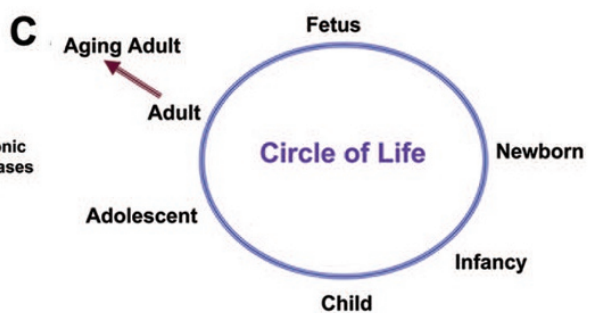

E

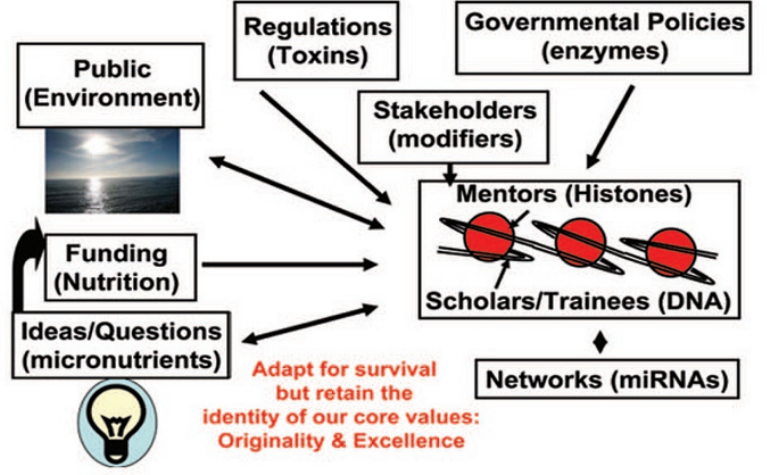

Figure 1. (A) Prevalence of overweight and obese children from 2 to $5 \mathrm{y}$ of age in United States. $\square$, overweight $=85-95 \%$ BMI for age; $\square$, obese $=95-100 \%$ BMI for age. $(B)$ World health imbalance. $(C)$ Circle of life. $(D)$ Vulnerabilities of Academic Pediatrics. (E). Epigenetics of Academic Pediatrics.

ity related to video games, television watching, and movies. Most of the television programming and movies come from Hollywood, which happens to be in my neighborhood. Let us examine how Hollywood may have contributed to the new world we live in. If we take the example of a recent movie that many of you may have seen, namely "Avatar," it is a science fiction that demonstrated significant technological advancement and portrayed blue characters with prominent ears and eyes along with tails. These characters demonstrated considerable physical activity but no obesity. This movie went far beyond globalization into another world. The main character was depicted as an individual who assumed a form to mingle with the "Navi" civilization and helped save them, their resources, and their way of life. Let us examine the origin of the term "Avatar"?

"Avatar" originates from a Sanskrit word "Avatara." Ava translates into "now" and tara into "star." This word translated into the description of deliberate descent of intermediaries from the stars in an assumed form to allow for easy mingling on earth. They possessed unique traits capable of bringing about a change in the Universe. In fact "Dasha" that translates into "10" "avataras" have been described, the evidence for which has been recorded on Indian ancient carvings on temple doors and antique tapestry. The description of these "avataras" from ancient times, halfway across the world before any technological or communication advancements, bears a close resemblance to Darwinism. The first "avatara" is the fish, which was the first developed life form; the second was tortoise, which followed the amphibians; the boar being the evolution to a land animal; the man-lion perhaps describing the ape-man (a missing link between apes and humans); the dwarf man being the first man; and the man with an axe bearing similarities to the modern man. The rest of the "avataras" depict improved cognition with the ability to lead as a
Table 1. Dasha Avātaras and Darwinism

\begin{tabular}{|c|c|c|}
\hline Avãtaras* & Translation & Biological explanation \\
\hline Matsya & Fish living in water & $\begin{array}{l}\text { First developed life form } \\
\quad \text { (Cambrian period) }\end{array}$ \\
\hline Kurma & Tortoise (reptiles) & $\begin{array}{l}\text { After amphibians first reptiles } \\
\text { emerged (Mississippian Period) }\end{array}$ \\
\hline Varaha & Boar & Evolution to land animal \\
\hline Narasimha & Man-lion & $\begin{array}{l}\text { May be ape man-missing link } \\
\text { between apes and humans }\end{array}$ \\
\hline Vamana & Dwarf man & First man (Pliocene Epoch) \\
\hline Parashurama & Man with an axe & $\begin{array}{l}\text { Similarities to modern man } \\
\text { (Quaternary period or Iron Age) }\end{array}$ \\
\hline
\end{tabular}

* Rest of the forms depict improved cognition.

king, recite poetry, and love peace (Table 1). Darwin and Lamarck described evolution "to favor the development of self-guiding mechanisms, maximizing variability where and when it is most likely to yield positive changes while minimizing phenotypic variability when and where it is not needed." But our current state in evolution has succumbed to high caloric diets and physical inactivity, resulting in the current phenotype of obesity. What is the biological mechanism responsible for this environment-gene or nutrition-gene interaction?

We now have the entire human genome sequenced, but a majority of the time, most of these conditions are not associated with gene mutations or rearrangements. Perhaps, it is the epigenome that plays a role. Epigenetics, which simply means "above genetics," refers to the heritable changes in gene function during cell replication that occurs without a change in the sequence of DNA. Epigenetics consists of DNA methylation, where methylation marks added to certain DNA bases repress gene activity, and the histone code, which consists of different molecules that attach to histone protein tails and alter the activity of DNA wrapped around them. Both processes are 
regulated by enzymes that pull and push the system and modifiers that ultimately alter the chromatin structure. It is the presence of these modifiers that make humans different from other mammalian species. Change in the ultimate chromatin structure dictates gene expression and thereby the presenting phenotype.

Let us meet two sets of sisters. The first set consists of the Agouti mouse sisters, where gene transcription from the unmethylated promoter region of the ectopic viable yellow agouti locus with an intracisternal A particle (transposan) yields a yellow coat color with an obese phenotype. When this promoter region is methylated, alternate transcription from the downstream endogenous agouti gene yields an agouti coat color with a lean body phenotype. Varying percent of promoter DNA methylation lends to intermediate mottled coat colors, which range from mild to heavy mottling. The other set of sisters express different diseases associated with aging due to differential DNA methylation signature patterns. Thus, this phenomenon also occurs in humans, although there are fewer methylated gene promoters in human versus mouse. Epigenome mapping in the future may help uncover disease specific DNA methylation marks of significance.

Looking at the agouti mouse sisters as an example, the coat color serves as a phenotypic marker of DNA methylation, showing the change from yellow to agouti coat color in the offspring based on supplementation of maternal diet with methyl donors, such as folic acid, vitamin B12, choline and betaine, or genistein. When exposed to an endocrine disruptor such as bisphenol A, an increase in the number of offspring with the yellow coat color and obesity is observed. This phenotype could be reversed to resemble that of control by introducing methyl donor micronutrients in maternal diet. A similar epigenetic process of control is operational in undernutrition and overnutrition of mothers as we have previously shown in the offspring.

More importantly, vertical transmission takes place by copying DNA methylation signatures from the template strand during replication, and copying silencing modifications from preexisting histones in the heterochromatin and activating modifications by "splitting hot spots" perhaps limited to the euchromatin.

In contrast, there is the more recent discovery of microRNAs that bind 3 '-untranslated regions of various genes degrading multiple mRNAs and/or causing translational arrest. This includes enzymes and modifier proteins that affect the process of epigenetics. However, micro-RNAs, in general, work on multiple genes that constitute a network and thereby work horizontally rather than vertically. Do these biological concepts of adaptation to the environment apply to Academic Pediatrics as we know it today?

To answer this question, it may be important to refresh our minds regarding the definition of "Academic Medicine" modified for "Academic Pediatrics." International Campaign to Revitalize Academic Medicine (ICRAM) in 2005 defined it as "the capacity of the system for health and health care of children to think, study, research, discover, evaluate, innovate, teach, learn, and improve." All these words describe the Originality and Excellence inherently present and serve as the identity of Academic Pediatrics. They further stated that "little could be more important, particularly because new discoveries in science offer tremendous opportunities, and emerging diseases pose huge threats. Indeed the contribution of Academic Pediatrics to child health over the last century has been extraordinary." However, they raised the concern as to whether Academic Pediatrics can lead the way into the twenty-first century? In response to this statement, the word "Translational Research" was coined. The definition of translational research by National Institutes of Health subsequently evolved over time. It was initially considered as a one-step process that moves basic sciences research from the laboratory to clinical practice. Next, it was considered to be a slow two-step process whereby basic biomedical discoveries are integrated into clinical practice first and second, result in improved health. It is now considered a four-step process, moving from basic scientific knowledge to theoretical knowledge as potential clinical application. Efficacy knowledge then leads to the development of evidence-based guidelines. This is followed by movement to applied knowledge in clinical care and finally to public health knowledge with application to community health. National Institutes of Health stated that by recognizing and addressing the complex steps of implementation down to the community level, translational research would stand a better chance of making a difference in outcomes for children and their families.

In an editorial, Campbell stated that "Medical schools and teaching hospitals in the United States are essential producers of basic scientific and clinical knowledge that drives our supply of new medicines, devices, and other health care innovations. Today, the funding for this work is dwindling, rendering the current structure of the biomedical research enterprise unsustainable. Given the economic crisis, the fiscal and operational models of this enterprise must be restructured if the stability of academic institutions is to be maintained and our growing health care needs are to be met" (2). What are the vulnerabilities of Academic Pediatrics? To be a successful leader in the twenty-first century, we must be a participant in scholarship. To lead scholarship, we must look at all three areas, as our training and clinical care responsibilities impact our performance at scholarship (Fig. 1D).

Under the scholarship arena, there is a changing face of funding agencies that are focused on "high impact projects" to be able to meet public demands. The high impact projects are viewed so based on the eyes of the beholder. In the big picture, projects considered of high impact with some amount of urgency to Pediatrics and children may not gain the "High Impact" status in the eyes of individuals who are responsible for prioritizing, particularly when the bigger bang for the buck is realized with projects of relevance to a larger population, namely adults. We have seen this in the pharmaceutical industry, which prioritizes drugs and devices with a larger market, and children do not provide this large a market. A similar phenomenon is seen with funding agencies under considerable public and/or governmental pressures. Despite the 2-y American Recovery and Reinvestment Act 2009 (ARRA) funding, the subsequent anticipation of a drop down a cliff has resulted in continuous grant writing activity expe- 
rienced by investigators as they join the $\mathrm{Q}$ for their turn at receiving funding. This has led to considerable investigator insecurity with a downward trend in their morale. There is increasing regulation and compliance requirements to conduct research. Expensive technology-driven science that generates reams of data are overtaking investigators with good biological questions that are relevant for providing cutting edge clinical care. Is not the latter truly "translational research"? Interdisciplinary team science is rarely shaped by Pediatric investigators. One must be careful that while it is important to participate in team science, because discoveries reside at the edges of multidisciplines, our specialty must not dwindle into merely becoming the patient recruiter or sample collector for the team with no intellectual input or involvement. This is increasingly seen where other disciplines are seeking Academic Pediatrics for such a role alone. There is overall a lack of adoption of an infrastructure that fosters scholarship. This is institution depended and highly variable across the country. This has led to the vanishing pediatrician-scientists and necessary role models for the next generation. We have all seen the loss of public trust in the research enterprise, investigators, and their data. A price paid by a majority of investigators for the actions by a few investigators.

In the case of our training responsibilities, The Institute of Medicine and the Accreditation Council for Graduate Medical Education (ACGME) regulations on training have led to unintended consequences of inadequate time to impart the required competencies. In this balancing act, sufficient time and priority for scholarship are fast disappearing. There is loss of experiential learning or the real thing. Any amount of simulations or didactic lecturing will not overcome this critical loss in training. All the other demands on faculty time have in essence reduced their time that can be devoted to actual training.

On the clinical care front, medical centers are running like businesses with differing priorities from that of Academic Pediatrics. These businesses believe that the priorities of Academic Pediatrics are misguided. Faculty productivity is gauged by relative value units, grant scores, and income generated as opposed to their ability to think, study, research, discover, evaluate, innovate, teach, learn, and improve, which defines Academic Pediatrics. Furthermore, the requirements for documentation have escalated and regulations mandating filling various forms, check lists, billing sheets, compliance training, and feeding information to databases in the name of transparency have collectively increased the computer face time for faculty. This issue threatens to become even more demanding with the birth of the electronic health record. Furthermore, the need to maintain competencies as it is disappearing in training programs, certifications, recertifications, and demonstration of compliance with mandated quality improvement activities in training and maintenance of certification consume faculty time that is not devoted to direct patient care. In general, we have adapted a protocol-oriented mentality with loss of creativity. Our increasing computer face time erodes patient-doctor relationship, because we no longer have the time with patients and parents as we spend increasing time with clinical care-related computer work. Again, we have in essence lost the public trust perhaps related to our medical errors, easy accessibility of medical information on the internet, and the media highlights of our shortcomings.

So what is the evolution of Academic Pediatrics? One sees a three-legged stool that was well-balanced previously. Today, we see that the clinical care leg is longer with a tendency to tip the stool over. This long clinical care leg is not devoted to direct patient care but rather to all the other nonpatient carerelated responsibilities that are mandated these days. In addition, the computer burden of various activities has resulted in increased administrative responsibilities related to all three legs of the stool. To survive this ever-changing environment, we must adapt or face extinction. How do we adapt? Can the principles of epigenetics, the science of biological adaptation, come to our rescue?

Our environment consists of the public demand that is ever changing similar to the biological environment, funding that is dwindling to the point of undernutrition and escalating regulations that mimic environmental toxins. The more developed our society, the more we have to contend with environmental toxins or in this case ever-increasing regulations. In this backdrop, we face the push and pull of governmental policies depending on who is presently in office, very much like the activating or silencing enzymes. Based on these enzyme activities, the local institutional stakeholders can either activate or repress support in the form of modifiers, required for faculty to undertake scholarly activities. If one imagines that faculty is the histone protein that does not change its core but is modified by having molecules bind its tail alone, one gets a picture of someone who is flexible enough to embrace new ideas and make a change, without changing their core values. They are responsible for vertical transmission of information fulfilled by their training responsibilities and this is accomplished by coming up with selective yet creative solutions to meet the present demands of compressed training. In addition, the faculty very much like histones influence the state of DNA wrapped around them. If one now envisions that this DNA is the trainee or a junior faculty colleague, it is important for this DNA to take cues from histones, but during replication, while becoming independent with new ideas, it is important to retain some of the original methylation marks of the parent strand. Hence, the DNA (trainee) must carry with them the original core values of the histone (faculty mentor's core values) and the parent DNA strand (faculty ideas and creativity). Some of us may choose to function like micro-RNAs and participate in networks; although this is an important activity for horizontal connections, this may not result in vertical transmission. In a large network study or team science what is the role of the trainee? Although faculty mentors are acknowledged in large lists of names appended to a manuscript, all trainees who may have participated are left forgotten. Hence, it is practice not to involve trainees in such large networks, yet are they not the next generation? But as with the agouti mouse sisters, nothing is possible without methyl donors or micronutrients, which I would suggest you equate to generation of innovative ideas and asking the relevant and pertinent questions (Fig. 1E).

Who better to generate innovative ideas and ask the important questions of relevance to children than pediatrician- 
scientists? They are the ones who are at the bedside and realize the clinical problems firsthand, and they are indeed the same ones who can take this back to either the laboratory or the clinical research group to seek the necessary answers. Unfortunately, pediatrician-scientists are vanishing. If no pediatrician-scientists are left, there may be no innovation or discovery in Academic Pediatrics. With no discovery, there may be nothing left to translate in "translational research." With discovery mainly based in non-Academic Pediatric disciplines, there may be no translation realized for the benefit of children. Discovery and translation must go hand in hand and mutually support each other in the discipline of Academic Pediatrics. Hence, although we may be forced to adapt to changing circumstances of health care, the upcoming health reform, and public demands, we must be open to new ideas and make a conscious effort to retain the identity of our core values, namely our originality and excellence.

How do we retain our identity of originality and excellence? We must ensure a system that lifts Academic Pediatrics above minimalistic expectations, similar to water lilies, where the flowers rise above the mud, water, and leaves. We must protect our competence and win back the public trust, guard against over regulation into near extinction, device a mandated infrastructure that supports scholarship in our discipline across the country, prevent tampering with the excitement for the next generation, and most importantly, foster time for creative thinking.

When one thinks of the recent Olympics that were held in our beautiful host city of Vancouver, what comes to mind are the goals of athletes. No matter where they came from, they showed us motivation and discipline, they practiced over and over again for long hours till proficient, they displayed ambition and perseverance, and at the end they demonstrated their talent and competence to the whole world. Although they may not have the longevity, we desire in our physician-scientists, the athletes hailed from a strong infrastructure and all of them with no exception reached for the gold. Why should we in Academic Pediatrics be any different? Instead of waiting for help from the stars in the form of yet another "Avatar," we must set high standards of originality and excellence for our specialty and reach for the stars. This goal will indeed translate into "Victory" or "Jai Ho" for Academic Pediatrics.
I will now turn my attention to the state of the APS in 2010. We began this year by garnering your opinion regarding the state of the APS. In keeping with your request, we launched a campaign to "Take back APS." It was clear you wished to retain your identity, your original signature namely a "unique leadership position." To deliver this to you, we undertook some initiatives, which consisted of creating an "APS day" to provide a small hut atmosphere within the big tent of the Pediatric Academic Societies (PAS) meetings; we took back the identity of the APS Presidential Plenary session; we formulated an APS member networking luncheon and an APS state of science session, followed by our traditional dinner to honor our Howland Awardee. In these activities, we wished to create palpable value for our members as they adapt to our changing environment. We also took on a strategic planning process on your behalf and identified some priority domains, namely, research advocacy, academic education, leadership coaching, internal and external communication, and improving the value of the PAS meeting for APS members. Although the implementation process has just begun in all these domains, we will be looking for your input to close the loop at our networking session and beyond, as you all stay involved in your Society. I would like to close by reiterating what a privilege it has been serving as your President and I thank you all for bestowing this honor on me. However, none of the work that was begun during my tenure on behalf of APS would be possible without our colleagues on council and the support of the APS staff. I would like to acknowledge how lucky I am to have so many professional relationships that I think of all of them as my own extended family. I would like to thank the many colleagues who are giants in our specialty and who generously allowed me to stand on their shoulders and helped me along the way by showing me the way to reach this podium today, and collaborators nationwide and worldwide. Finally, it is all about the world's children that we are all privileged to serve. I thank you for this honor.

\section{REFERENCE}

1. Ogden CL, Carroll MD, Curtin LR, Lamb MM, Flegal KM 2010 Prevalence of high body mass index in US children and adolescents, 2007-2008. JAMA 303:242-249.

2. Campbell, EG 2009 The future of research funding in academic medicine. N Eng J Med 360;1482-1483. 